\title{
Electromyographic Analysis of the Orbicularis Oris Muscle in Oralized Deaf Individuals
}

\author{
Simone Cecílio Hallak REGALO ${ }^{1}$ \\ Mathias VITTI ${ }^{1}$ \\ Maria Tereza Bagaiolo MORAES ${ }^{2}$ \\ Marisa SEMPRINI ${ }^{1}$ \\ Cláudia Maria de FELÍCIO² \\ Maria da Glória Chiarello de MATTOS 3 \\ Jaime Eduardo Cecílio HALLAK ${ }^{4}$ \\ Carla Moreto SANTOS ${ }^{3}$ \\ ${ }^{1}$ Department of Morphology, Stomatology and Physiology, Faculty of Dentistry of Ribeirão Preto, \\ University of São Paulo, Ribeirão Preto, SP, Brazil \\ ${ }^{2}$ Department of Speech Pathology and Audiology, University of Ribeirão Preto (UNAERP), Ribeirão Preto, SP, Brazil \\ ${ }^{3}$ Department of Dental Materials and Prosthodontics, Faculty of Dentistry of Ribeirão Preto, \\ University of São Paulo, Ribeirão Preto, SP, Brazil \\ ${ }^{4}$ Department of Neuropsychiatry and Psychological Medicine, Medical School of Ribeirão Preto, University of São Paulo, \\ Ribeirão Preto, SP, Brazil; Neuroscience and Psychiatry Unit, University of Manchester, Manchester, UK
}

\begin{abstract}
Electromyography has been used to evaluate the performance of the peribuccal musculature in mastication, swallowing and speech, and is an important tool for analysis of physiopathological changes affecting this musculature. Many investigations have been conducted in patients with auditory and speech deficiencies, but none has evaluated the musculature responsible for the speech. This study compared the electromyographic measurements of the superior and inferior fascicles of the orbicularis oris muscle in patients with profound bilateral neurosensorial hearing deficiency (deafness) and healthy volunteers. Electromyographic analysis was performed on recordings from 20 volunteers (mean age of 18.5 years) matched for gender and age. Subjects were assigned to two groups, as follows: a group formed by 10 individuals with profound bilateral neurosensorial hearing deficiency (deaf individuals) and a second group formed by 10 healthy individuals (hearers). Five clinical conditions were evaluated: suction, blowing, lip projection and compression, and production of the syllable "Pa". It was found that the deaf patients presented muscle hyperactivity in all clinical conditions, and that the inferior fascicle of the orbicularis oris muscle showed higher electromyographic activity rates, suggesting the need for a hearingspeech treatment with emphasis on oral motricity.
\end{abstract}

Key Words: electromyography, deafness, orbicularis oris muscle.

\section{INTRODUCTION}

Hearing loss can be defined as any impairment in hearing that reduces the intelligibility of any received spoken message in such a way that it causes difficulty to reach an accurate interpretation and in the learning process. Gravel and O’Gara(1) described the importance of language skills in the development and life of an individual with hearing deficiencies. This fact highlights the need to help children with hearing deficiencies.

Speech therapy has been used to aid children with auditive deficits to develop language skills, mainly speech (2). Because speech production is one of the goals of speech therapy, electrophysiologic studies that investigate speech perception comparing the facial musculature activity in deaf and normal individuals could be helpful to develop strategies and methods to make speech more comprehensible $(3,4)$. 
Electromyography (EMG) has been used to investigate the different muscular physiopathology affecting the temporomandibular joint, masticatory, facial and peribuccal musculature, during activities such as mastication, swallowing and speech (5-9).

The orbicularis oris muscle is composed of two parts: the superior fascicle and the inferior fascicle. Several studies have pointed out that they are separate structures and work in a complex way during multiple lip positioning, with different levels of activity (10).

Because most deaf patients seem to present strong dysfunction in facial and masticatory musculatures, the purpose of this study was to analyze and describe, using electromyography, the functional characteristics of the superior and inferior fascicles of the orbicularis oris muscle in patients with profound neurosensorial hearing deficiency.

\section{MATERIAL AND METHODS}

This study was carried out at the Electromyography and Computerized Occlusal Diagnosis Laboratory of the Department of Morphology, Stomatology and Physiology of the Faculty of Dentistry of Ribeirão Preto (USP).

Two groups of ten patients matched according to gender (five male and five female per group) and age (mean age of 18.5 years) were formed as follows: a group was composed of 10 individuals with profound bilateral neurosensorial hearing deficiency (deaf patients) and a second group was composed of 10 individuals clinically healthy (hearers), nose breathers, with normal occlusion, who acted as controls.

Auditory evaluation comprised pure tone audiometry to evaluate the hearing threshold and impedance audiometry to verify middle ear conditions. In pure tone audiometry, the test is presented to the patient's ear by air conduction (through a monoaural ear phone) at frequencies of 125, 250, 500, 1000, 2000, 4000 and $8000 \mathrm{~Hz}$. A clearly audible tone is first presented. As soon as the patient hears the tone, he/she signals to the examiner by raising his/her hand. The examiner reduces the tone to an intensity that is inaudible to the patient and then successively increases it in $5 \mathrm{~dB}$ steps, until the patient responds again. If hearing threshold level of a patient is greater than $25 \mathrm{~dB}$, an audiogram should be done to confirm a possible impairment (11). An acoustic bridge inserted into the external auditory canal that generates a pure tone reflected from the eardum can determine the middle ear impedance. Adjustments are made so that the reflected sound is balanced within the bridge. A distinctive pattern of change in impedance with change in pressure differentiates conditions, such as middle ear being normal, pathologically negative pressure, fluid in the middle ear or disrupted osteo chain.

The auditory evaluation was carried out using a clinical audiometer (model AC-40; Interacoustic, Assens, Denmark) for pure tone audiometry and an impedancemeter (model AT22; Interacoustic) for impedance of middle ear. The auditory evaluation confirmed the diagnosis of profound bilateral neurosensorial hearing loss in half of the volunteers selected for this study (deaf group).

Electromyographic recordings of the superior and inferior fascicles of the orbicularis oris muscle were used to evaluate muscle activity during situations that involved effective lip participation: suction of water through a straw (Suction), Blowing through a straw (Blowing), Lip Projection, Reciprocal compression of lips (Lip Compression), Production of the syllable "Pa". Prior to performing the movements, patients were given instructions and practiced, imitating the examiner.

The K6-I EMG Eight Channel Surface Electromyograph (Myotronics Co., Seattle, WA, USA) was used to record the EMG activity. The electrodes applied were disposable duotrodes, with silver-chloride surface, $10 \mathrm{~mm}$ diameter and $21 \mathrm{~mm}$ inter-electrode distance (Duotrodes; Myotronics Co.), containing a conductive gel (Myogel; Myotronics Co.). The electrodes were positioned centrally and parallel to the direction of the fiber bundles of each fascicle of the orbicularis oris muscle. The skin was cleaned with alcohol to decrease impedance. A reference electrode was placed next to the patient's nape

A very calm and silent environment was created during the electromyographic register. The room had little light and the patient was seated on a comfortable chair (office type), in upright position with feet resting on the floor and arms resting on the legs. The head was in an upright position and the Frankfurt posture/plan was used as a positioning parameter.

Necessary instructions and explanations were given before each record and the patients were asked to be as calm as possible, breathing slowly. The patients signed a written informed consent form for 
electromyography research, according to the 196/96 Resolution of the Brazilian National Health Council, approved by the Ethics in Human Research Committee of the University of São Paulo (USP).

Statistical analysis was done using the SPSS software version 10.0 for Windows (SPSS Inc., Chicago, IL, USA). Continuous data with normal distribution were analyzed by univariate analysis of variance (ANOVA). Significance level was set at $\mathrm{p}=0.05$. ANOVA was used to compare the EMG activity of the orbicularis oris muscle in deaf patients and hearers, and EMG activity of the superior and inferior fascicles of the orbicularis oris muscle in the different clinical conditions (regardless of the group). EMG activity means obtained under the five tested conditions was assessed using Bonferroni correction for multiple comparisons. ANOVA was also used to compare the EMG activity in the superior and inferior fascicles during different clinical conditions in both deaf and healthy patients, separately.

\section{RESULTS}

Data in Table 1 shows that during all clinical conditions the orbicularis oris muscle of deaf patients presented higher EMG levels than that of healthy volunteers, with statistically significant difference $(\mathrm{p}<0.05)$ during blowing, lip compression and pronunciation of the syllable " $\mathrm{Pa}$ ".

In addition, the inferior fascicle of the orbicularis oris muscle showed higher EMG levels than the superior fascicle in all clinical conditions, except for blowing. Statistically significant difference $(\mathrm{p}<0.05)$ was detected during lip projection and pronunciation of syllable " $\mathrm{Pa"}$ (Table 2).

Table 1. Electromyographic activity of the orbicularis oris muscle (means in microvolts \pm standard error) during the different clinical activities (suction, blowing, projection, compression and syllable "Pa”) in control and deaf groups.

\begin{tabular}{lccccc}
\hline Activity & Control $(\mathrm{n}=10)$ & Deaf $(\mathrm{n}=10)$ & $\mathrm{F}$ & $\mathrm{df}$ & $\mathrm{p}$ \\
\hline Suction & $43.52 \pm 7.85$ & $55.07 \pm 7.12$ & 1.19 & 1 & 0.28 \\
Blowing* & $37.57 \pm 4.77$ & $54.40 \pm 6.37$ & 4.47 & 1 & 0.04 \\
Projection & $72.88 \pm 11.79$ & $90.58 \pm 8.31$ & 1.51 & 1 & 0.23 \\
Compression* & $42.73 \pm 4.62$ & $84.25 \pm 12.76$ & 9.36 & 1 & 0.00 \\
Syllable "Pa”* & $32.67 \pm 4.60$ & $57.60 \pm 8.49$ & 6.66 & 1 & 0.01 \\
\hline
\end{tabular}

* Statistically significant difference at $\mathrm{p}<0.05$.

Table 2: Electromyographic activity (means in microvolts \pm standard error) of the superior fascicle and inferior fascicle of the orbicularis oris muscle during the different clinical activities (suction, blowing, projection, compression and syllable "Pa”).

\begin{tabular}{lccccc}
\hline Activity & Superior $(\mathrm{n}=20)$ & Inferior $(\mathrm{n}=20)$ & $\mathrm{F}$ & $\mathrm{df}$ & $\mathrm{p}$ \\
\hline Suction & $47.58 \pm 6.14$ & $51.02 \pm 8.83$ & 0.10 & 1 & 0.75 \\
Blowing & $49.61 \pm 6.17$ & $42.36 \pm 5.61$ & 0.76 & 1 & 0.39 \\
Projection* & $65.04 \pm 7.64$ & $98.41 \pm 11.34$ & 5.95 & 1 & 0.02 \\
Compression & $57.34 \pm 7.42$ & $69.64 \pm 13.06$ & 0.67 & 1 & 0.42 \\
Syllable "Pa"* & $27.88 \pm 2.82$ & $62.39 \pm 8.39$ & 15.20 & 1 & 0.00 \\
\hline
\end{tabular}

* Statistically significant difference at $\mathrm{p}<0.05$. 
The orbicularis oris muscle presented different levels of EMG activity during the different clinical conditions $(\mathrm{F}=6.74, \mathrm{p}<0.01)$. Multiple comparisons showed that the highest levels of activity were achieved during lip projection, differing from all other clinical conditions $(\mathrm{p}<0.05)$.

Figure 1 shows the comparison of EMG activity between deaf and healthy volunteers for the superior fascicle of the orbicularis oris muscle during the different clinical conditions. For all clinical conditions, higher EMG activity means were observed in deaf patients, but statistically significant difference $(\mathrm{p}<0.05)$ was found

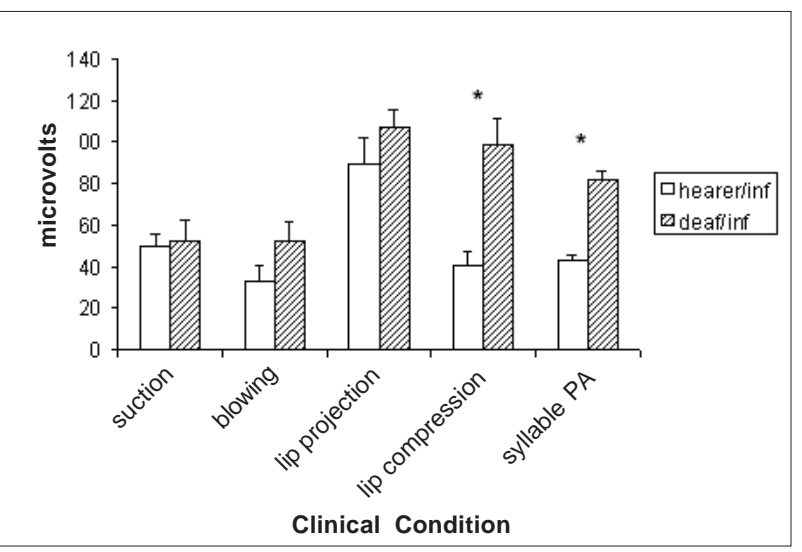

Figure 2. EMG activity means (in microvolts) of the inferior fascicle of the orbicularis oris muscle during the clinical conditions for healthy and deaf patients. The vertical bars represent standard error. * indicates statistically significant difference at $\mathrm{p}<0.05$.

\section{DISCUSSION}

Electromyography has been used to investigate the performance of peribuccal musculature in several physiological processes, such as mastication, swallowing and speech.

The results of this study confirmed that, under the clinical conditions evaluated, individuals with profound hearing deficiency had higher EMG levels of the orbicularis oris muscle (both superior and inferior fascicles). These findings are consistent with those of a recent study (12) that reported an increased electromyographic activity in the orbicularis oris musculature of deaf individuals who used only LIBRAS (Brazilian Sign Language) to communicate.

Different electromyographic means were found only for production of the syllable "Pa" $(\mathrm{F}=5.17 \mathrm{df}=$ $1, \mathrm{p}=0.03)$.

Figure 2 shows the comparison of EMG activity between deaf and healthy volunteers for the inferior fascicle of the orbicularis oris muscle during the different clinical conditions. Similarly to what happened with the superior fascicle, it was observed that, in all clinical conditions, EMG activity means were higher in deaf subjects than in healthy volunteers. This difference was statistically significant for lip compression $(\mathrm{F}=6.33$, df $=1, \mathrm{p}=0.02)$ and production of the syllable " $\mathrm{Pa}$ " $(\mathrm{F}=$ 6.78, $\mathrm{df}=1, \mathrm{p}=0.02)$.

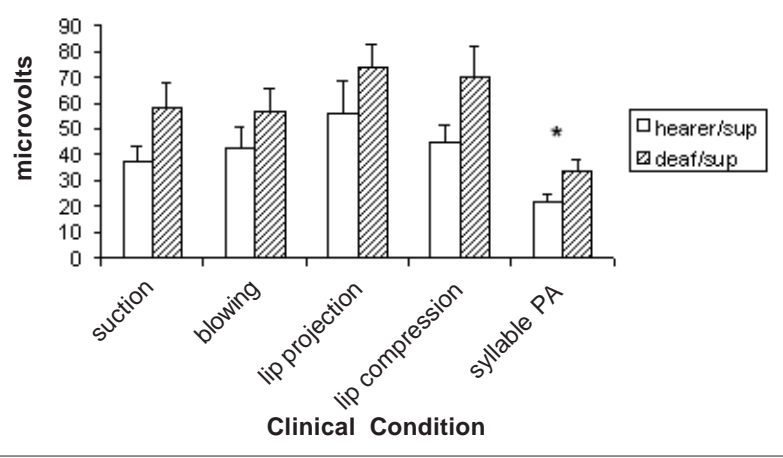

Figure 1. EMG activity means (in microvolts) of the superior fascicle of the orbicularis oris muscle during the clinical conditions for healthy and deaf patients. The vertical bars represent standard error. * indicates statistically significant difference at $\mathrm{p}<0.05$.

when comparing the superior and inferior fascicles, which confirms the independence of superior and inferior labial activity, also reported by several authors $(10,13)$.

Regarding the difference between the superior and inferior fascicles of the orbicularis oris muscle, it was found that the inferior fascicle presented a higher electromyographic activity during clinical activities, which is in agreement with the outcomes of previous studies $(14,15)$.

Our results are similar to those from Barlow and Rath (16), who found higher action potentials for the inferior fascicle of the orbicularis oris muscle with better strength control and movement accuracy through menton synergy, while Tosello et al. (9) reported higher activity of the inferior fascicle in comparison to the 
superior fascicle at suction movement.

It is known that the facial and labial muscles contribute to the production of vowels, bilabial phonemes, labiodentals phonemes and for oral communication in general because they provide the visual aids for speech perception of phonemes and the suitable facial expressions, which come with them.

Speech is a sensorimotor process that involves the regulation of active force among many muscle systems of the vocal tract (17). Speech motor control refers to the systems and strategies that control the production of speech. It is assumed that the input to the system of speech control is a phonologic representation of language. The output of speech control is a series of articulatory movements that convey an acoustic signal that can be interpreted by a listener (18).

The movement-generated sensory experiences are presumed important for motor control and formulation of perioral space during neural development (17). Individuals with profound hearing loss have a deficit in language input and motor experience. The higher electromyographic activity of the orbicularis oris muscle for production of the syllable "Pa" suggests a lack of coordination from oral motor control for specific task demands.

Production of bilabial phonemes at typical conversation rates and intensities does not involve large muscular forces. Normal speakers typically use less than $20 \%$ of available inter-labial contact pressure (19).

Further studies focusing on other facial muscles, particularly the masticatory musculature, should be conducted to verify whether this increased muscle activity is present, which could cause overload of the temporomandibular joint.

Based on the data from this study, it may be concluded that: 1) In different clinical conditions (suction, blowing, lip projection, compression and production of the syllable "Pa"), higher levels of EMG activity were found for the superior and inferior fascicles of the orbicularis oris muscle in patients with profound neurosensorial hearing deficiency, in comparison to healthy individuals (hearers); 2) EMG activity during lip projection significantly differed from all other clinical conditions, showing the highest electromyographic activity of all; 3) The inferior fascicle of the orbicularis oris muscle showed higher electromyographic activity rates, suggesting the need for speech therapy with emphasis on oral motricity.

\section{RESUMO}

A eletromiografia, como método de estudo, tem sido bastante utilizada e vem contribuindo para elucidar o desempenho da musculatura peribucal em vários processos fisiológicos como a mastigação, deglutição e fala, e é um instrumento importante na análise das bases fisiopatológicas das mudanças que ocorrem nesta musculatura. Muitos trabalhos têm sido conduzidos em pacientes com deficiência auditiva e de fala, mas nenhum deles avaliou a musculatura responsável pela fala. Este estudo comparou medidas eletromiográficas dos fascículos superior e inferior do músculo orbicular da boca em indivíduos portadores de deficiência auditiva neurossensorial profunda (surdos) com indivíduos clinicamente normais (ouvintes). A análise eletromiográfica foi realizada em 20 indivíduos, de ambos os sexos, com idade média de 18,5 anos, divididos em dois grupos: o primeiro grupo constituído por 10 indivíduos portadores de deficiência auditiva neurossensorial profunda bilateral e o segundo por indivíduos clinicamente normais. Cinco condições clínicas foram avaliadas: sucção, sopro, projeção e compressão labial e emissão da sílaba "Pa". Verificou-se que os pacientes surdos apresentaram hiperatividade muscular em todas as condições clínicas analisadas, e que o fascículo inferior do músculo orbicular da boca apresentou os níveis mais altos de atividade eletromiográfica, sugerindo a necessidade de um tratamento fonoaudiológico, com enfoque em motricidade oral.

\section{ACKNOWLEDGEMENTS}

The authors acknowledge FAPESP (grant number 02/02473-9) for financial support. We are also grateful to Jason Dunham and Jane Lees (Department of Psychiatry and Behavioural Sciences, University of Manchester, UK) for English corrections and suggestions on the manuscript.

\section{REFERENCES}

1. Gravel JS, O'Gara J. Communication options for children with hearing loss. Ment Retard Dev Disabil Res Rev 2003;9:243-251.

2. Ferrari DV, Bevilacqua MC. Comparison between digital and hybrid hearing aids - part I: loudness growth measures. ProFono Rev Atual Ci 2003;15:75-84.

3. Mchenry MA, Mintom JT, Wison RL, Post YV. Intelligibility and nonspeech orofacial strength and force control following traumatic brain injury. J Speech Hear Res 1994;37:12711283.

4. Forrest K, Weismer G. Dynamic aspects of lower lip movement in parkinsonian and neurologically normal geriatric speakers' production of stress. J Speech Hear Res 1995;38:260-272.

5. Fromkin VA. Neuromuscular specification of linguistic units. Lang Speech 1966;9:170-199.

6. MacNeilage PF, Declerk JL. On the motor control of coarticulation in CVC monosyllables. J Acoust Soc Amer 1969;45:1217-1233.

7. Lubker JF, Parris PJ. Simultaneous measurements of intraoral pressure, force of labial contact, and labial electromyographic activity during production of stop consonant cognates $/ \mathrm{p} /$ and 
/b/. J Acoust Soc Am 1970;47:625-633.

8. Tosello DO, Vitti M, Bérzin F. EMG activity of the orbicularis oris and mentalis muscles in children with malocclusion, incompetent lips and atypical swallowing - part I. J Oral Rehabil 1998;25:838-846.

9. Tosello DO, Vitti M, Bérzin F. EMG activity of the orbicularis oris and mentalis muscles in children with malocclusion, incompetent lips and atypical swallowing - part II. J Oral Rehabil 1999;26:644-649.

10. Basmajian JV, De Luca CJ. Muscles alive: their function revealed by electromyography. 5th ed. Baltimore: Williams and Wilkins; 1985.

11. Paparella MM, Shumrick DA. Otolaryngology. Basic sciences and related disciplines. Philadelphia: WB Saunders; 1973.

12. Regalo SCH, Semprini M, Vitti M, Lopes RA, Mattos MGC, Constancio RJ, Pegoraro ME, Hallak JEC. EMG - analysis of the upper and lower fascicles of the orbicularis oris muscle in bilingual deaf individuals. Electromyogr Clin Neurophysiol 2003;43:367-372.

13. Nieberg LG. An electromyographic and radiographic investigation of the orofacial muscular complex. Am J Orthod 1960;46:927-928.
14. Møller E. The chewing apparatus. An electromyographic study of the action of the muscles of mastication and its correlation to facial morphology. Acta Physiol Scand 1966;69(suppl.):280.

15. Subtelny JD, Sakuda M. Muscle function, oral malformation, and growth changes. Am J Orthod 1966;52:495-517.

16. Barlow SM, Rath EM. Maximum voluntary closing forces in the upper and lower lips of humans. J Speech Hear Res 1985;28:373-376.

17. Andreatta RD, Barlow SM, Biswas A, Finan D. Mechanosensory modulation of perioral neuronal groups during active force dynamics. J Speech Hear Res 1996;39:1006-1017.

18. Kent RD. Research on speech motor control and its disorders: a review and prospective. J Commum Disord 2000;33:391428.

19. Hinton VA, Arokiasamy WMC. Maximum interlabial pressures in normal speakers. J Speech Lang Hear Res 1997;40:400-404. 